\title{
An Optimization Model of Tunnel Support Parameters
}

\author{
Su Lijuan ${ }^{1, *}$, Liu Haiqing ${ }^{1}$, Qiao Chunsheng ${ }^{2}$, Zhen Ying ${ }^{1}$ and Hong Shenwei ${ }^{3}$ \\ ${ }^{I}$ College of Civil Engineering and Architecture, Liaoning Technical University, Fuxin 123000, China \\ ${ }^{2}$ School of Civil Engineering, Beijing Jiao tong University, Beijing 100044, China \\ 2 Technology Center for AUNNR Construction Co.Ltd., D/ Nabel Porres, 109, Santander, Spain
}

Received 6 April 2015; Accepted 25 May 2015

\begin{abstract}
An optimization model was developed to obtain the ideal values of the primary support parameters of tunnels, which are wide-ranging in high-speed railway design codes when the surrounding rocks are at the III, IV, and V levels. First, several sets of experiments were designed and simulated using the FLAC ${ }^{3 \mathrm{D}}$ software under an orthogonal experimental design. Six factors, namely, level of surrounding rock, buried depth of tunnel, lateral pressure coefficient, anchor spacing, anchor length, and shotcrete thickness, were considered. Second, a regression equation was generated by conducting a multiple linear regression analysis following the analysis of the simulation results. Finally, the optimization model of support parameters was obtained by solving the regression equation using the least squares method. In practical projects, the optimized values of support parameters could be obtained by integrating known parameters into the proposed model. In this work, the proposed model was verified on the basis of the Liuyang River Tunnel Project. Results show that the optimization model significantly reduces related costs. The proposed model can also be used as a reliable reference for other high-speed railway tunnels.
\end{abstract}

Keywords: high-speed railway; rock stability; optimization model; support parameters

\section{Introduction}

High-speed railways are widely used in China, and their construction necessitates the digging of many tunnels. Generally, high-speed railway tunnels are supported by composite linings, hence, the values of primary support parameters (i.e., anchor length, anchor spacing, and shotcrete thickness) are particularly critical (the support parameters described here refer to the primary support parameters for high-speed railway tunnels). However, professional norms provide a range of values for tunnel support parameters. Unfortunately, the methods for scientifically determining the best values of support parameters and their ideal combinations remain unclear. Therefore, designers must optimize the existing models of support parameters in the process of high-speed railway construction.

On the basis of extensive research data, several geological and support factors were selected for modeling on the FLAC $^{3 \mathrm{D}}$ software. All the simulation schemes were implemented according to an orthogonal experimental design, and the results were analyzed through multiple linear regression. The model demonstrating the relation between the parameters and cost-effectiveness could then be obtained Thereafter, the constraints for the optimization model were deduced with the least squares method. The ideal values of the support parameters could ultimately be determined by combining the values of the geological conditions and safety levels. Practical projects were used to validate the

* E-mail address: su_ljd@163.com ISSN: 1791-2377 @ 2015 Kavala Institute of Technology. All rights reserved. optimization model, and the results show that the optimization model for support parameters can save the cost efficently.

\section{Description of the problem}

Tunnel surrounding rock is divided into six levels in the high-speed railway design code. Six levels are I, II, III, IV, $\mathrm{V}$, and VI. Support parameters can easily be determined in a high-speed railway design code, when the levels of surrounding rocks are I and II. However, a range of values are specified when the levels of surrounding rocks are III, IV, and $\mathrm{V}$. In practical projects, values of tunnel support parameters are mainly given by designers [1-3]. Because of the complex geological conditions, and the lack of systematic theoretical guidance, some designers tend to use conservative values to ensure tunnel safety, but such practice can result in a waste of resources and high costs, but other designers tend to use smaller supporting strength in order to save costs, and this will lead to large security risk during the process of building and operation. Therefore, how to determine the ideal values of primary support parameters which is an important issue in high-speed railway tunnel construction, when the levels of surrounding rocks are III, $\mathrm{IV}$, and V [4]. Our experimental study is conducted only when the level of surrounding rocks is IV.

\section{State of the art}

Liu established the relationship between displacement and structural stiffness first and taken the minimum deformation 
pressure which spray anchor suffered as the objective function; finally he obtained reasonable support parameters using model optimized by penalty function [5]. Xia developed back propagation neural network model of shaft and tunnel support parameters and trained it by large number of successful engineering data [6]. Wang implemented to optimize the tunnel primary support parameters, taken its surrounding rock bolt and anchor not damaged as the objective function, and received reasonable support parameters [7]. Zheng analyzed the stress state of anchor under different arrangement, got the best layout of anchor at different levels of surrounding rock in soft rock tunnel [8]. Wang analyzed the bolting and grouting mechanism, optimized anchor grouting parameters using orthogonal design, determined the main factors, got ideal support scheme [9].

In short, although there were great developments in the surrounding rock and supporting area, many problems still existed in the theory and supporting design. Due to the lack of optimization study in high-speed railway tunnel supporting field, related research was carried out in this paper.

\section{Methodology}

The methodology of this research is composed of three geological factors and three supporting factors which are considered for modeling. The FLAC ${ }^{\mathrm{D}}$ finite difference program was used in this study for modeling and calculation.

\subsection{Selection of parameters}

Based on several project studies, theoretical analyses, characteristics of level IV rocks, and relevant specifications, the support materials used in this study are as follows: $\phi 22$ cement mortar anchors with a plum-shaped layout and shotcrete of $\mathrm{C} 25$. The selection of the mechanical parameters for tunnel support is important because it directly determines whether the simulation results are reasonable. The values of the mechanical parameters in this study are selected on the basis of several studies on ongoing high-speed railway construction projects $[10,11]$. The parameters are shown in Tables 1 and 2.

\begin{tabular}{|c|c|c|c|c|c|}
\hline $\begin{array}{l}\text { Style of } \\
\text { support } \\
\text { structure }\end{array}$ & $\begin{array}{l}\text { Elastic } \\
\text { modulus } \\
(\mathrm{E} / \mathrm{GPa})\end{array}$ & $\begin{array}{l}\text { Bulk } \\
\text { modulus } \\
(\mathrm{K} / \mathrm{GPa})\end{array}$ & $\mu$ & $\Phi / /^{\circ}$ & Sectional area $\left(\mathrm{m}^{2}\right)$ \\
\hline $\begin{array}{l}\phi \quad 22 \\
\text { cement } \\
\text { mortar } \\
\text { anchor }\end{array}$ & 210 & 120 & 0.2 & 35 & $0.314 \mathrm{E}-3$ \\
\hline
\end{tabular}

\begin{tabular}{|c|c|c|c|c|c|}
\hline $\begin{array}{l}\text { Style of } \\
\text { upport } \\
\text { tructure }\end{array}$ & $\begin{array}{l}\text { Severe } \\
\left(\mathrm{KN} / \mathbf{m}^{3}\right)\end{array}$ & $\begin{array}{l}\text { Elastic } \\
\text { modulus(E/GPa) }\end{array}$ & $\begin{array}{l}\text { Poisson's } \\
\text { ratio v }\end{array}$ & $\begin{array}{l}\text { Compressi } \\
\text { ve strength } \\
\text { (MPa) }\end{array}$ & $\begin{array}{l}\text { Tensile } \\
\text { strengtl } \\
\text { (MPa) }\end{array}$ \\
\hline $\begin{array}{l}\text { shotcrete } \\
\text { C25 }\end{array}$ & 23 & 29.5 & 0.2 & 12.5 & 1.33 \\
\hline
\end{tabular}

Many factors affect the final results of support schemes, and the interactions between these factors are unknown; in simplifying existing models, geological and support factors are typically selected for simulation [12]. Geological factors include tunnel depth, level of surrounding rock, and lateral pressure coefficient. Support factors include anchor length, anchor spacing, and shotcrete thickness. Both the effect of the main factors and their interaction between them are unknown. However, they can be estimated through an orthogonal experimental design [13]. The experimental scheme in this work is developed with an orthogonal experiment design involving the factors and parameters are shown in Table 3. Factors such as the physical and mechanical parameters of surrounding rocks, tunnel depth $\mathrm{H}$, lateral pressure coefficient $\lambda$, anchor length $\mathrm{L}$, anchor spacing $\mathrm{a}$, and shotcrete thickness $\mathrm{h}$ are considered in the orthogonal design. The physical and mechanical parameters of surrounding rock include density $\gamma$, internal friction angle $\varphi$, cohesion $\mathrm{C}$, elastic modulus E, and Poisson's ratio. The levels of these parameters are shown in Table 3.

Table 3. Levels of factors and parameters

\begin{tabular}{ccccccccccc}
$\begin{array}{c}\text { Factor } \\
\text { levels }\end{array}$ & $\begin{array}{c}\text { Physical and mechanical parameters of surrounding rocks } \\
\text { Density } \Gamma \\
\left(\mathrm{KN} / \mathrm{m}^{3}\right)\end{array}$ & $\begin{array}{c}\text { Internal } \\
\text { friction } \\
\text { angle } \varphi\left({ }^{\circ}\right)\end{array}$ & $\begin{array}{c}\text { Cohesion } \\
C(\mathrm{MPa})\end{array}$ & $\begin{array}{c}\text { Elastic } \\
\text { modulus } E \\
(\mathrm{GPa})\end{array}$ & $\begin{array}{c}\text { Poisson's } \\
\text { ratio } \mu\end{array}$ & $\begin{array}{c}\text { Depth } \\
H(\mathrm{~m})\end{array}$ & $\begin{array}{c}\text { Lateral } \\
\text { pressure } \\
\text { coefficient } \lambda\end{array}$ & $\begin{array}{c}\text { Anchor } \\
\text { length } \\
L(\mathrm{~m})\end{array}$ & $\begin{array}{c}\text { Anchor } \\
\text { spacing } \\
a(\mathrm{~m})\end{array}$ & $\begin{array}{c}\text { Shotcrete } \\
\text { thickness } \\
h(\mathrm{~mm})\end{array}$ \\
\hline 1 & 23 & 39 & 0.7 & 6 & 0.35 & 160 & 1 & 2.0 & 1.0 & 150 \\
2 & 22.25 & 36 & 0.575 & 4.825 & 0.3375 & 320 & 1.25 & 2.25 & 1.05 & 167.5 \\
3 & 21.5 & 33 & 0.45 & 3.65 & 0.325 & 480 & 1.5 & 2.5 & 1.1 & 185.0 \\
4 & 20.75 & 30 & 0.325 & 2.475 & 0.3125 & 640 & 1.75 & 2.75 & 1.15 & 202.5 \\
5 & 20 & 27 & 0.2 & 1.3 & 0.3 & 800 & 2 & 3.0 & 1.2 & 220.0 \\
\hline
\end{tabular}

\subsection{Modeling}

FLAC $^{3 \mathrm{D}}$ is used to modeling and calculation with aforementioned parameters. The dimensions of the numerical model are as follows: the upper depth is five times the tunnel span, the depth of the lower part is thrice the span, and the left and right sides are thrice the span. The height, width, and depth of the model are 80,60 , and $20 \mathrm{~m}$, respectively. The cross section of the tunnel is a standard profile of a dual carriageway provided in the specifications. Figure 1 shows the model size, whereas Figure 2 shows the mesh.

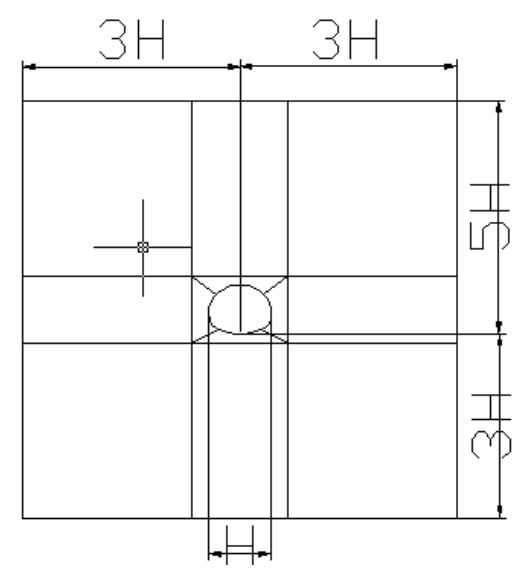


Fig.1. Model size

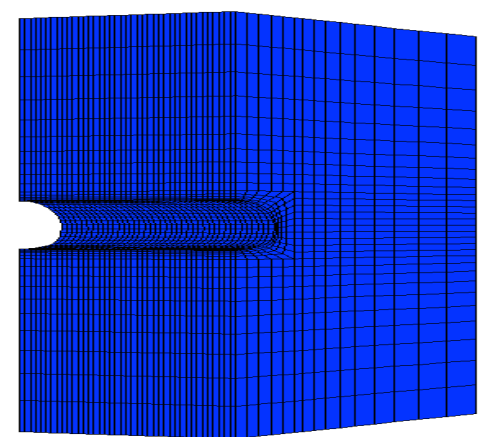

Fig.2. Model mesh

High-speed railway tunnels are supported by composite linings. Anchors and shotcrete are used for primary support, whereas cast-in-place concrete is used for secondary linings [14]. The primary support tends to bear all the pressure of the surrounding rock, whereas secondary linings only serve as a safety margin and are used to improve waterproof levels [15-18]. Therefore, secondary linings are excluded in the simulation in the present work. A cable unit and shell elements in FLAC ${ }^{3 \mathrm{D}}$ are used for the anchor and shotcrete simulation. Figures 3 and 4 show the cable units and shell elements, respectively.

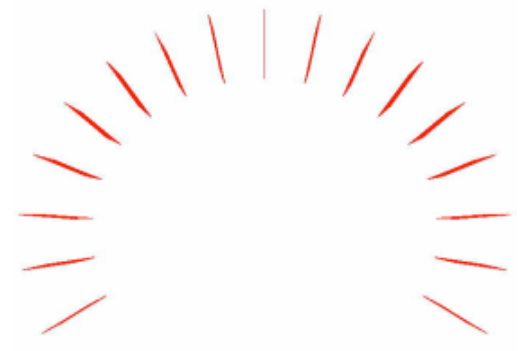

Fig. 3. Anchor simulation

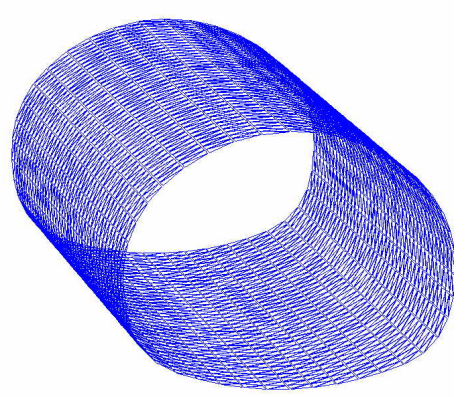

Fig. 4. Shotcrete simulation

\subsection{Scheme evaluation}

After simulation, each supporting scheme should be evaluated for subsequent optimization. The safety degree of the plastic zone is considered as the safety level, whereas the cost-effectiveness of the schemes (i.e., the ratio of safety degree and economic indicators) is regarded as the evaluation indicator of the support schemes. The evaluation steps are as follows:

First, the convergence displacement and convergence ratio are used as the mechanical criteria for the comprehensive determination of surrounding rock stability. The rock is deemed stable if and only if the displacements and strength requirements are met [19-21]. The unstable support schemes are removed according to the said criterion.

Second, $u_{f}$ is defined as the safety degree of the support scheme according to the numerical simulation results. $u_{f}$ is then calculated according to Equation (1).

$$
u_{f}(i)=\frac{V(i)-V_{\min }}{V_{\max }-V_{\min }}
$$

where $u_{f}(i)$ refers to the safety degree of the i-th scheme, $V(i)$ refers to the plastic zone volume in the i-th scheme, $V_{\min }$ refers to the smallest volume of the plastic zone in all schemes, and $V_{\max }$ refers to the maximum volume of the plastic zone in all schemes.

The cost $A$ and economic indicator $u_{a}$ for the remaining schemes are then calculated.

The costs of excavation per meter remain the same when the cross section is left unchanged. Thus, only the costs of the support materials are considered. With the Liaoning Province as an example, $A$ is calculated in Yuan $/ \mathrm{m}$ using Equation (2) according to the 2008 National Inventory Valuation Norms.

$$
A(i)=\frac{K_{i} \times N_{j} \times 20}{L}+m
$$

where $A(i)$ refers to the cost of the i-th scheme (unit: Yuan $/ \mathrm{m}$ ), $K_{i}$ refers to the cost of a single anchor (unit: Yuan), and $\mathrm{i}=1,2,3$. When $\mathrm{i}=1, K_{i}=36$; when $\mathrm{i}=2, K_{i}=40.5$; when $\mathrm{i}=3, K_{i}=45$; when $\mathrm{i}=4, K_{i}=49.5$; and when $\mathrm{i}=5, K_{i}$ $=54 . N_{j}$ refers to the number of anchors in a single cross section, $L$ refers to the tunnel length (unit: $\mathrm{m}$ ), and $m$ is the shotcrete cost in Yuan $/ \mathrm{m}$. When the shotcrete thickness is $150 \mathrm{~mm}, m=1,820$; when the shotcrete thickness is 167.5 $\mathrm{mm}, m=2,032$; when the shotcrete thickness is $185 \mathrm{~mm}, m$ $=2,245$; when the shotcrete thickness is $202.5 \mathrm{~mm}, m=$ 2,457 ; and when the shotcrete thickness is $220 \mathrm{~mm}, m=$ 2,670 . The economic indicator is calculated according to the cost $A$ and Equation (3).

$$
u_{a}(i)=\frac{A(i)-A_{\min }}{A_{\max }-A_{\min }}
$$

$F_{V}$ is used as the cost-effective indicator and then calculated for each scheme.

$$
F_{V}(i)=\frac{u_{f}(i)}{u_{a}(i)}
$$

\subsection{Optimization}

Calculation of the safety degree and the cost-effectiveness of each supporting program, the relationship between supporting parameters and cost-effectiveness can be obtained by further analysis. Then, the function between them can be established through multiple linear regression analysis.

Multivariate linear regression can be expressed as follows: 


$$
F_{V}=t+b_{1} \times u_{f}+b_{2} \times H+b_{3} \times \lambda+b_{4} \times a+b_{5} \times l+b_{6} \times h
$$

where $t$ is a constant to be determined and $b_{i}(\mathrm{i}=1,2,3,4,5$, $6)$ is the partial regression coefficient. By considering $y$ as $F_{V}$, the sum of the residual square in the multiple linear regressions can be expressed as follows:

$$
S_{e}=\sum_{j=1}^{n}\left(y_{j}-t-b_{1} u_{f j}-b_{2} H_{j}-b_{3} \lambda_{j}-b_{4} a_{j}-b_{5} l_{j}-b_{6} h_{j}\right)^{2}
$$

where $n$ is the number of test schemes. Let $X=\left[u_{f}, H, \lambda, a, l, h\right]$. The partial derivative of the sum of the residual squares to $t$ and $b_{i}$ is as follows:

$$
\left\{\begin{array}{l}
\frac{\partial S_{e}}{\partial t}=-2 \sum_{j=1}^{n}\left(y_{j}-t-b_{1} u_{f 1 j}-b_{2} H_{2 j}-b_{3} \lambda_{3 j}-b_{4} a_{4 j}-b_{5} l_{5 j}-b_{6} h_{6 j}\right) \\
\frac{\partial S_{e}}{\partial b_{i}}=-2 \sum_{j=1}^{n} x_{i j}\left(y_{j}-t-b_{1} u_{f 1 j}-b_{2} H_{2 j}-b_{3} \lambda_{3 j}-b_{4} a_{4 j}-b_{5} l_{5 j}-b_{6} h_{6 j}\right)
\end{array}\right.
$$

where $x_{i}$ is the i-th element in $\mathrm{X}, x_{i j}$ is the value of $x_{i}$ in the $\mathrm{j}$-th experimental scheme, and $y_{j}$ is the value of $\mathrm{y}$ in the $\mathrm{j}$-th experimental scheme. $E x_{i}$ is considered as the mean of $x_{i j}$, and $E y$ is considered as the mean of $y_{j} . L_{i k}(i, k=1,2,3,4,5$, 6)and $L_{i y}$ are then derived as follows:

$$
\left\{\begin{array}{l}
L_{i k}=L_{k i}=\sum_{j=1}^{n}\left(x_{i j}-E x_{i}\right)\left(x_{k j}-E x_{k}\right)=\sum_{j=1}^{n} x_{i j} x_{k j}-\frac{1}{n} \sum_{j=1}^{n} x_{i j} \sum_{j=1}^{n} x_{k j} \\
L_{i y}=\sum_{j=1}^{n}\left(x_{i j}-E x_{i}\right)\left(y_{j}-E y\right)=\sum_{j=1}^{n} x_{i j} y_{j}-\frac{1}{n} \sum_{j=1}^{n} x_{i j} \sum_{j=1}^{n} y_{j}
\end{array}\right.
$$

By expanding Equation (7) and combining it with Equation (8), the equations of the matrix form can then be obtained as follows:

$$
\left[\begin{array}{cccc}
L_{11} & L_{12} & \ldots & L_{16} \\
L_{21} & L_{22} & \cdots & L_{26} \\
\mathrm{M} & \mathrm{M} & \ldots & \mathrm{M} \\
L_{61} & L_{62} & \cdots & L_{66}
\end{array}\right]\left[\begin{array}{l}
b_{1} \\
b_{2} \\
\mathrm{M} \\
b_{6}
\end{array}\right]=\left[\begin{array}{l}
L_{1 y} \\
L_{2 y} \\
\mathrm{M} \\
L_{6 y}
\end{array}\right]
$$

Thereafter, $b_{i}$ can be solved using the least squares method. Finally, $t$ can be solved using Equation (7). Then, the coefficients in the equation 5 are solved. Using Equation
(5) as a basic model, the optimization scheme can be established on the basis of the above regression analysis. According to the principle of least squares, optimization constraints can be obtained by considering the anchor length $l$, anchor spacing $a$, and shotcrete thickness $h$, when setting the three partial derivatives to zero in certain geological conditions and safety degrees.

$\left\{\begin{array}{l}\frac{\partial F_{V}}{\partial a}=f_{1}(a, l, h)=0 \\ \frac{\partial F_{V}}{\partial l}=f_{2}(a, l, h)=0 \\ \frac{\partial F_{V}}{\partial h}=f_{3}(a, l, h)=0\end{array}\right.$

By expanding the above equation and incorporating the values of the geological conditions and safety level into it, the detailed optimization model can be obtained.

\section{Experimental results and discussion}

We must first determine the effect of support parameters on rock stability to obtain the optimal model of tunnel support parameters. The stability of surrounding rock is reflected in the changes in the plastic zone and stress distribution, as well as in the displacement of the key points of tunnel cross section. Therefore, recording these changes during excavation is necessary.

\subsection{Impact of support parameters}

Three support parameters are considered in this study to analyze the impact of surrounding rock stability. We used anchor spacing as an example. Under the constant conditions of other factors, anchor spacing was individually changed when simulating the tunnel excavation process under different anchor spacing values. The anchor spacing values were $a=1.0,1.05,1.1,1.15,2.0 \mathrm{~m}$. According to the changes in the plastic zone, the stress distribution, and displacement of the critical points in the cross section, we could analyze their effects on the stability of the surrounding rocks. The plastic zone distributions after excavation are shown in Figure 6. The major principal stress and minor principal stress distributions around the tunnel when $a=1.0$ $\mathrm{m}$ are shown in Figure 7.

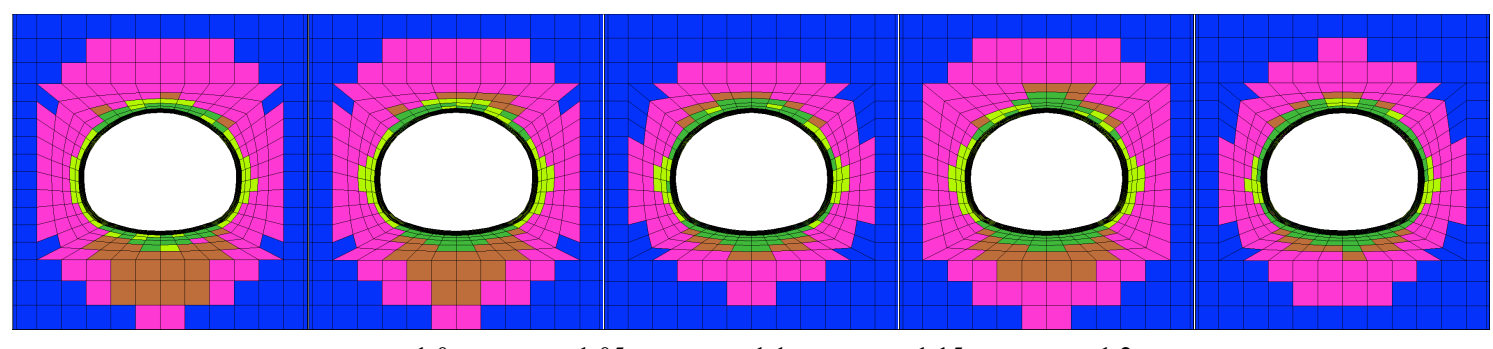

Fig.6. Plastic zone distributions 


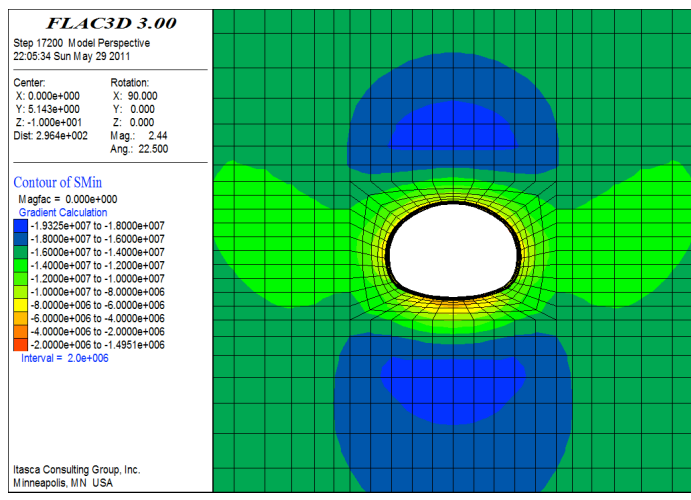

Fig.7. Stress field distribution when $a=1.0 \mathrm{~m}$

Figure 7 shows the stress distribution when $a=1.0 \mathrm{~m}$. The major principal stress of the arch and bottom was 4.2 $\mathrm{MPa}$, that of the spandrel was $2.3 \mathrm{MPa}$, and that of the arch foot was 8.0 MPa. The minor principal stress of the tunnel

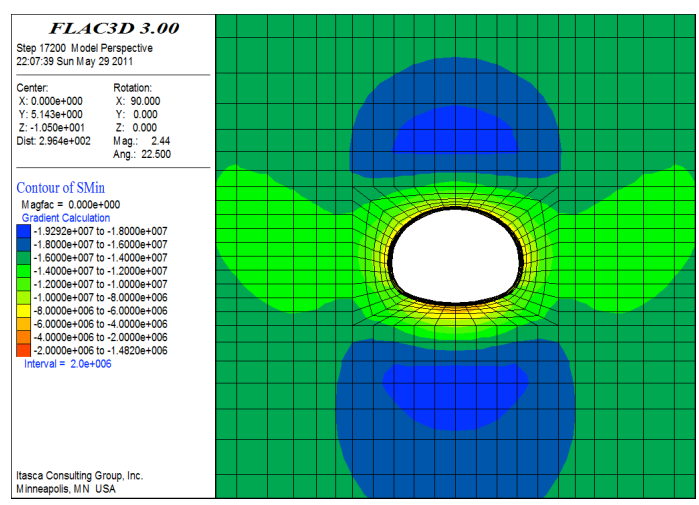

Fig.8. Stress field distribution when $a=1.05 \mathrm{~m}$

Figure 8 shows the stress distribution when $a=1.05 \mathrm{~m}$. The major principal stress of the arch and bottom was 4.2 $\mathrm{MPa}$, that of the spandrel was $2.2 \mathrm{MPa}$, and that of the arch foot was 8.1 MPa. The minor principal stress of the tunnel

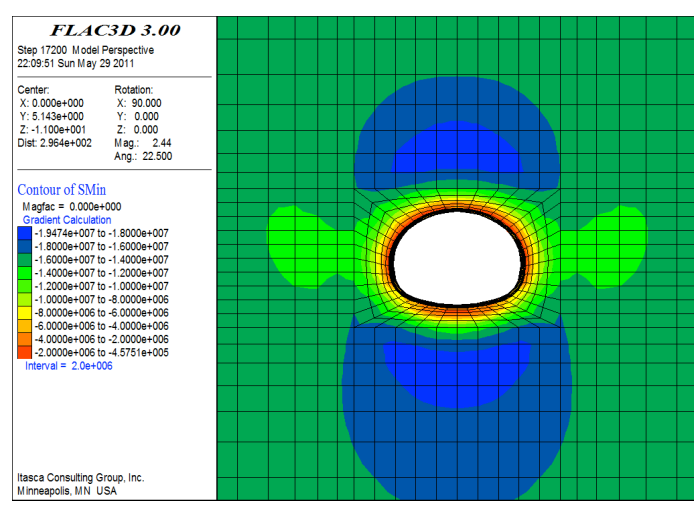

Fig.9. Stress field distribution when $a=1.1 \mathrm{~m}$

Figure 9 shows the stress distribution when $a=1.1 \mathrm{~m}$. The major principal stress of the arch and bottom was 3.5 $\mathrm{MPa}$, that of the spandrel was $2.0 \mathrm{MPa}$, and that of the arch foot was 7.3 MPa. The minor principal stress of the tunnel

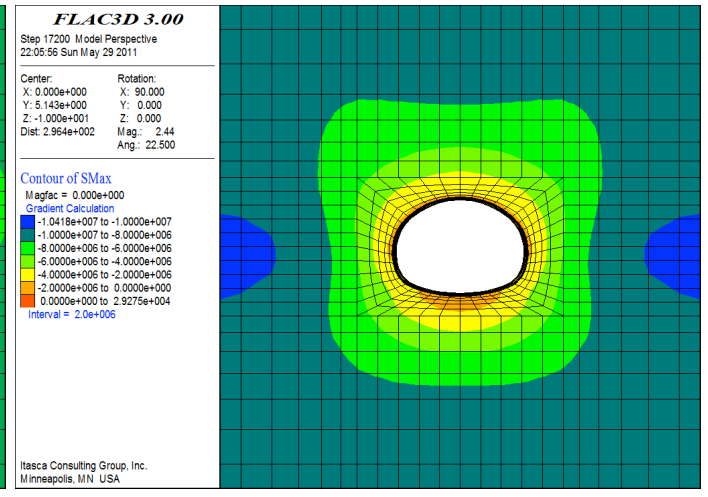

periphery was $2.0 \mathrm{MPa}$.

The major principal stress and minor principal stress distributions around the tunnel when $a=1.05 \mathrm{~m}$ are shown in Figure 8.

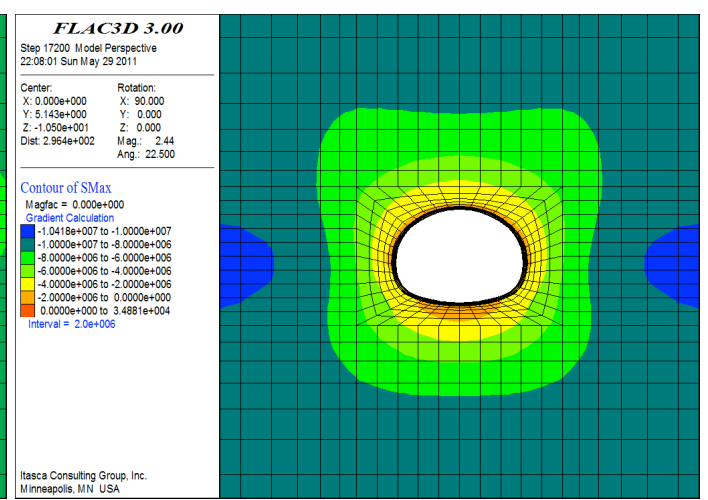

periphery was $2.0 \mathrm{MPa}$.

The major principal stress and minor principal stress distributions around the tunnel when $a=1.1 \mathrm{~m}$ are shown in Figure 9.

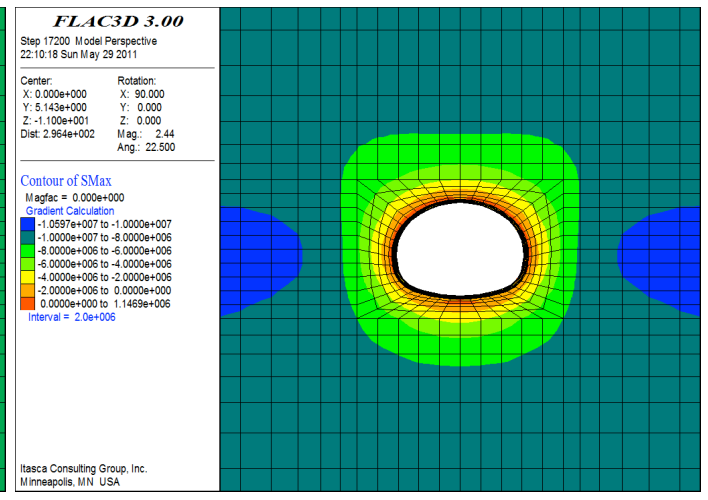

periphery was $1.2 \mathrm{MPa}$.

The major principal stress and minor principal stress distributions around the tunnel when $a=1.15 \mathrm{~m}$ are shown in Figure 10. 

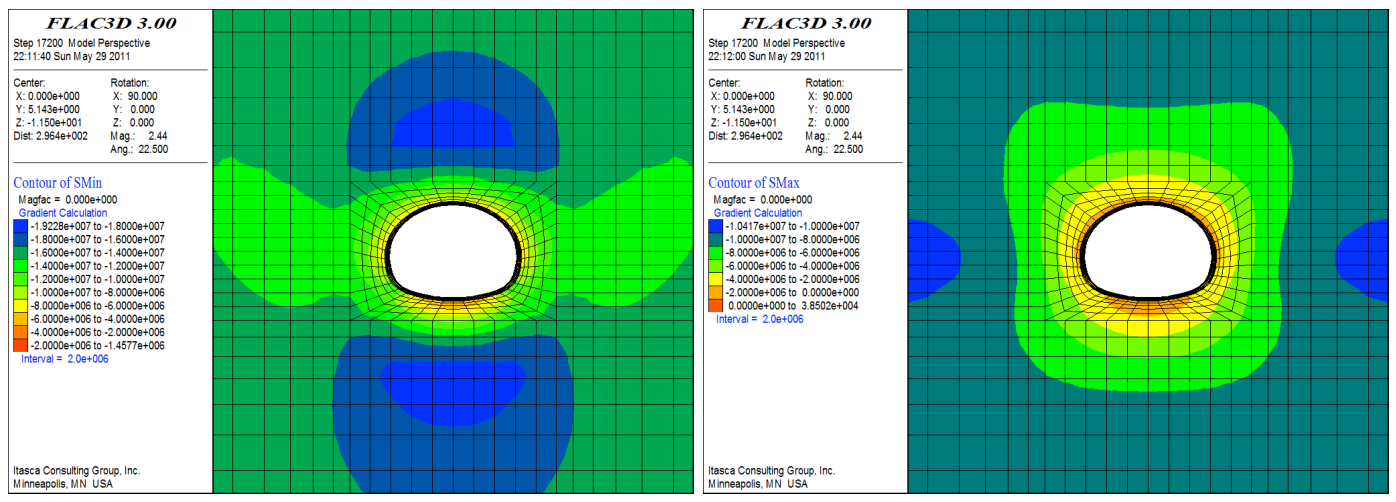

Fig.10. Stress field distribution when $a=1.15 \mathrm{~m}$

Figure 10 shows the stress distribution when $a=1.15 \mathrm{~m}$. The major principal stress of the arch and bottom was 5.5 $\mathrm{MPa}$, that of the spandrel was $2.4 \mathrm{MPa}$, and that of the arch foot was 8.6 $\mathrm{MPa}$. The minor principal stress of the tunnel periphery was $2.1 \mathrm{MPa}$.

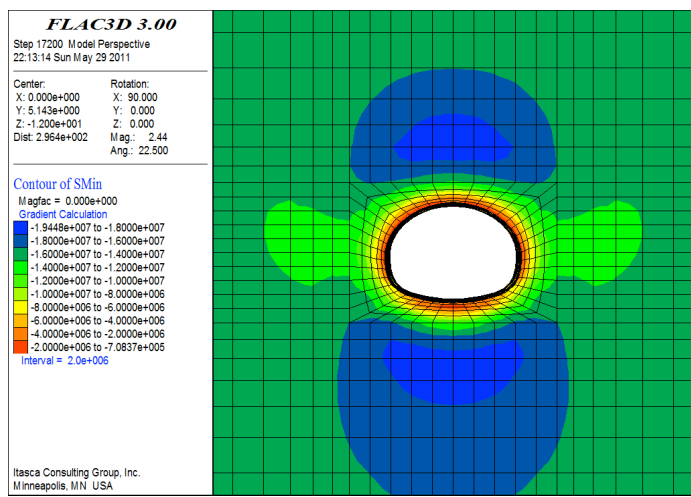

Fig.11. Stress field distribution when $a=1.2 \mathrm{~m}$

Figure 11 shows the stress distribution when $a=1.2 \mathrm{~m}$. The major principal stress of the arch and bottom was 3.8 $\mathrm{MPa}$, that of the spandrel was $2.1 \mathrm{MPa}$, and that of the arch foot was $7.5 \mathrm{MPa}$. The minor principal stress of the tunnel periphery was $1.3 \mathrm{MPa}$.

Ten monitoring cross sections are set along the direction of the tunnel excavation, and six key points in the vault, dome, left spandrel, right spandrel, left arch foot, and right arch
The major principal stress and minor principal stress distributions around the tunnel when $a=1.2 \mathrm{~m}$ are shown in Figure 11.

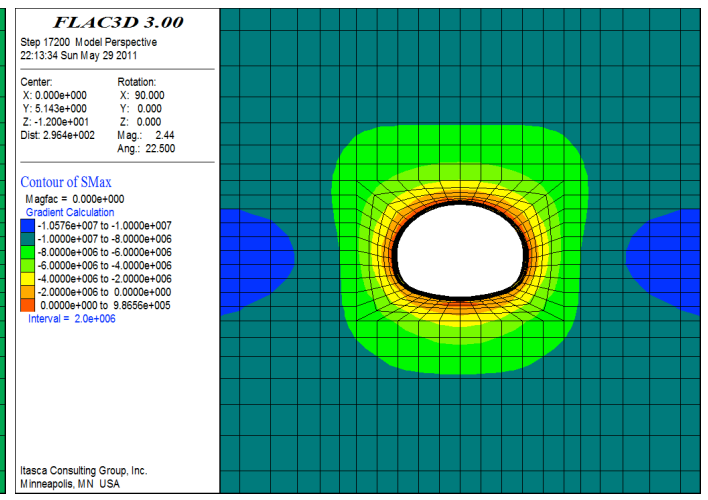

foot are set in each cross section before calculation to study the effect of anchor spacing on the displacement of the tunnel's surrounding rocks. The influence of changes in anchor spacing on the displacements of surrounding rocks can be shown clearly by monitoring the displacement of these key points. The displacement results are plotted in Figures 12(a) and 12(b).

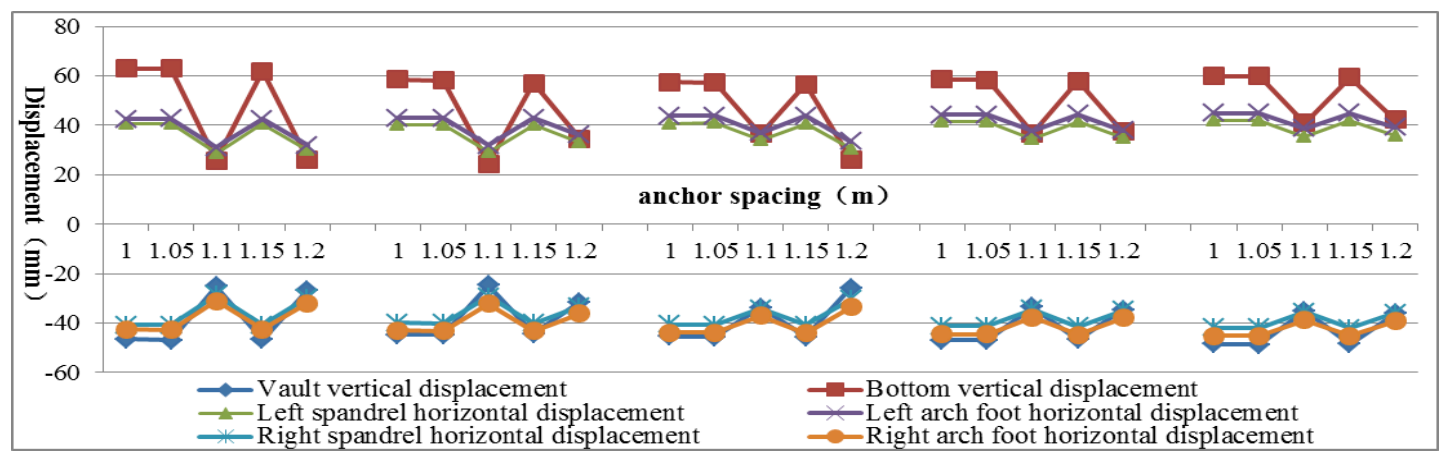

Fig.12. (a) Displacements of key points 


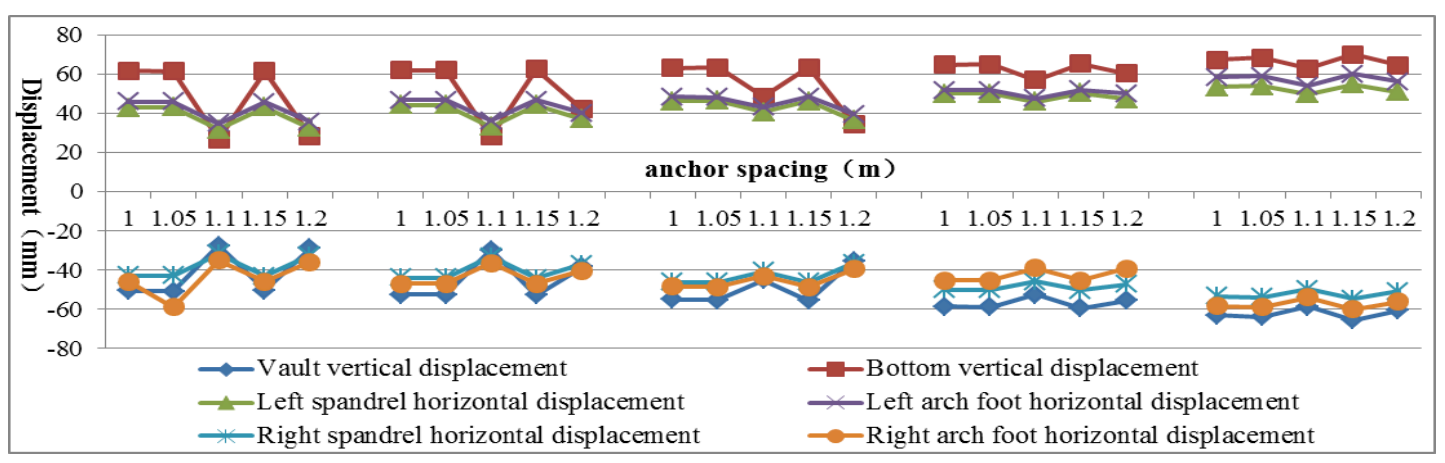

Fig.12. (b) Displacements of key points

As shown in Figure 12, the displacements of the key points are almost the same when the anchor spacing is increased from $1.0 \mathrm{~m}$ to $1.05 \mathrm{~m}$ in the same cross section. However, all of the displacements of the key points decrease when the anchor spacing is increased from $1.05 \mathrm{~m}$ to $1.1 \mathrm{~m}$, whereas all of the displacements of the key points increase when the anchor spacing is increased from $1.1 \mathrm{~m}$ to $1.15 \mathrm{~m}$. All of the displacements of the key points decrease when the anchor spacing is increased from $1.15 \mathrm{~m}$ to $1.2 \mathrm{~m}$.

We can derive the following conclusions by comparing the displacements of the six key points shown in Figure 12. The vault and dome displacements are the largest, followed by the arch and spandrel displacements. The latter excavation displacements are smaller than the earlier ones, thus indicating that the rock displacements change over time during the excavation.

In addition, the simulation results reveal the influence of anchor length and shotcrete thickness on the surrounding rock support. All figures are not listed in this paper because of space limitations.

The major principal stresses of the vault and arch bottom decrease from 2.2 $\mathrm{MPa}$ to $1.8 \mathrm{MPa}$, when the anchor length is increased from $2.0 \mathrm{~m}$ to $3.0 \mathrm{~m}$. However, no significant change in the major principal stress is observed when the anchor length is increased from $2.5 \mathrm{~m}$ to $2.75 \mathrm{~m}$. Overall, the changes in the major principal stress and minor principal stress are minimal as the bolt length increased.
In terms of displacement, the displacements of the six key points on the same monitoring cross section are almost unchanged with the increase in the bolt length. These results indicate that the change in the anchor length had little effect on the stability of the surrounding rocks.

When the shotcrete thickness is increased from $15 \mathrm{~cm}$ to $22 \mathrm{~cm}$ and the other factors are unchanged, the major principal stresses of the vault and arch bottom increase from 4.0 $\mathrm{MPa}$ to 5.0 $\mathrm{MPa}$. The major principal stress of the arch foot also increase from 2.2 MPa to 3.1 MPa. The changes of the major principal stress on the two sides of the tunnel are also similar. The changes in the main stress reflect a monotonous increase with the increase in the shotcrete thickness.

With the increase in the shotcrete thickness, the displacements of the key points in the same cross section decrease and exhibit a monotonically decreasing trend. Therefore, the increased shotcrete thickness benefitted the stability of the surrounding rocks.

\subsection{Indicators of supporting schemes}

The safety degree and the cost-effectiveness of each supporting program can be accessed according to the simulation results and corresponding formulas in section 4.3.The indicator results of the simulated schemes are shown in Table 4.

\begin{tabular}{|c|c|c|c|c|c|c|c|c|c|c|c|}
\hline $\begin{array}{l}\text { Test } \\
\text { number }\end{array}$ & $\begin{array}{c}\text { Safety } \\
\text { degree }\end{array}$ & Cost & $\begin{array}{l}\text { Cost-effective } \\
\text { indicators }\end{array}$ & $\begin{array}{l}\text { Test } \\
\text { number }\end{array}$ & $\begin{array}{l}\text { Safety } \\
\text { degree }\end{array}$ & Cost & $\begin{array}{l}\text { Cost-effective } \\
\text { indicators }\end{array}$ & $\begin{array}{l}\text { Test } \\
\text { number }\end{array}$ & $\begin{array}{l}\text { Safety } \\
\text { degree }\end{array}$ & Cost & $\begin{array}{l}\text { Cost-effective } \\
\text { indicators }\end{array}$ \\
\hline 1 & 0.99 & 2792 & 3.53 & 18 & 0.77 & 3943 & 1.96 & 35 & 0.83 & 3421 & 2.42 \\
\hline 2 & 0.88 & 3073 & 2.88 & 19 & 0.73 & 3047 & 2.41 & 36 & 0.85 & 3247 & 2.62 \\
\hline 3 & 0.92 & 3268 & 2.81 & 20 & 0.59 & 2752 & 2.14 & 37 & 0.76 & 3518 & 2.16 \\
\hline 4 & 0.88 & 3447 & 2.55 & 21 & 0.56 & 3157 & 1.76 & 38 & 0.75 & 3684 & 2.02 \\
\hline 5 & 0.85 & 3705 & 2.29 & 22 & 0.75 & 3325 & 2.25 & 39 & 0.86 & 3390 & 2.53 \\
\hline 6 & 0.98 & 3570 & 2.74 & 23 & 0.62 & 3147 & 1.97 & 40 & 0.78 & 2596 & 2.99 \\
\hline 7 & 0.90 & 2769 & 3.25 & 24 & 0.41 & 3764 & 1.09 & 41 & 0.81 & 2900 & 2.78 \\
\hline 8 & 0.79 & 3490 & 2.26 & 25 & 0.00 & 2977 & 0.00 & 42 & 0.62 & 2722 & 2.27 \\
\hline 9 & 0.72 & 3171 & 2.28 & 26 & 1.00 & 3406 & 2.94 & 43 & 0.76 & 3339 & 2.27 \\
\hline 10 & 0.88 & 3377 & 2.61 & 27 & 0.90 & 4128 & 2.19 & 44 & 0.70 & 3614 & 1.94 \\
\hline 11 & 0.87 & 3846 & 2.25 & 28 & 0.85 & 2746 & 3.11 & 45 & 0.66 & 3795 & 1.75 \\
\hline 12 & 0.84 & 3488 & 2.42 & 29 & 0.88 & 2952 & 2.97 & 46 & 0.51 & 3711 & 1.37 \\
\hline 13 & 0.69 & 2630 & 2.62 & 30 & 0.82 & 3145 & 2.60 & 47 & 0.74 & 2891 & 2.57 \\
\hline 14 & 0.84 & 2895 & 2.89 & 31 & 0.98 & 3063 & 3.20 & 48 & 0.60 & 3022 & 1.98 \\
\hline 15 & 0.76 & 3582 & 2.11 & 32 & 0.91 & 3267 & 2.78 & 49 & 0.41 & 3280 & 1.24 \\
\hline 16 & 0.82 & 3021 & 2.73 & 33 & 0.86 & 3533 & 2.43 & 50 & 0.04 & 3429 & 0.11 \\
\hline
\end{tabular}




\begin{tabular}{llll|llll|l}
\hline 17 & 0.58 & 3672 & 1.57 & 34 & 0.71 & 3157 & 2.23 & \\
\hline
\end{tabular}

\subsection{Optimization model}

After the analysis of the numerical experiment results, the relationship between each support parameter and costeffectiveness can be derived (Figure 13).

Figure 13 shows that an approximate linear relationship exists between different factors and cost-effectiveness. Anchor spacing and cost-effectiveness are positively correlated. The other parameters are negative. Therefore, a multiple linear regression model can be established as a function of support parameters and cost-effectiveness.

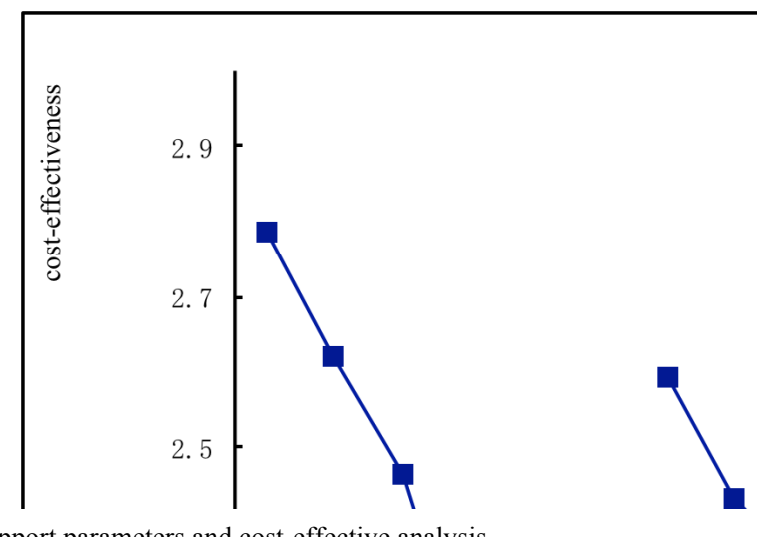

Fig.13. Support parameters and cost-effective analysis

Figure 13 shows that an approximate linear relationship exists between different factors and cost-effectiveness. Anchor spacing and cost-effectiveness are positively correlated. The other parameters are negative. Therefore, a multiple linear regression model can be established as a function of support parameters and cost-effectiveness.

By incorporating the values in Table 3 into Equation (9), the values of bi in the experiment can be calculated. Finally, by incorporating $b_{i}$ into Equation (7), the regression equation can be obtained as follows:

$$
F_{V}=2.839-0.314 A-0.001 H-0.554 \lambda-0.182 a+2.932 l-0.073 h
$$

The results of the analysis are shown in Table 5.

Table 5. Analysis of variance

\begin{tabular}{ccccccc}
\hline Variance Source & $\begin{array}{c}\text { Sum of squared } \\
\text { deviations }\end{array}$ & Freedom & $\begin{array}{c}\text { Variance } \\
\text { (mean square) }\end{array}$ & F value & F $_{\mathbf{0 . 1}}(\mathbf{6 , 4 3})$ & Significance \\
\hline Regress & 14.0644 & 6 & 2.3441 & 11.4124 & 3.239 & $* *$ \\
Residuals & 8.8336 & 43 & 0.2054 & & & \\
Sum & 22.898 & 49 & & & & \\
\hline
\end{tabular}

As that $\mathrm{F}>\mathrm{F} 0.01(6,43)$, the regression equation is highly significant.

By incorporating the values of the geological conditions and safety level of our experiments into Equation (11), as a result detailed optimization model is obtained when the levels of surrounding rock are III, IV.

$$
\left[\begin{array}{l}
a \\
l \\
h
\end{array}\right]=\left[\begin{array}{ccc}
2.753 & 2.753 & -2.753 \\
0.171 & 0.171 & 0.171 \\
-6.810 & 6.810 & 6.810
\end{array}\right]\left[\begin{array}{l}
-15.591+0.866 A+0.003 H+1.526 \lambda \\
-1.9085+0.161 A+0.001 H+0.284 \lambda \\
-40.036+2.141 A+0.007 H+3.776 \lambda
\end{array}\right](12
$$

In practical engineering applications, the optimal support scheme can be obtained by incorporating the corresponding values of the geological conditions and safety level under specific projects into Equation (12).

\subsection{Application}

The Liuyang River Tunnel is a key project of the WuhanGuangzhou Line, which is the first railway tunnel through the city, river, and highway. It is a long tunnel located in the eastern part of Changsha City, Hunan Province. It has a total length of $10.115 \mathrm{~km}$. The maximum width of excavation exceeds $16 \mathrm{~m}$, the excavation height is more than $13 \mathrm{~m}$, and the cross-sectional area is more than $160 \mathrm{~m} 2$. The average depth of the tunnel is between 50 and $60 \mathrm{~m}$. The tunnel is rare among Chinese railway tunnels [22].

The values of the primary support parameters for the surrounding rock in level IV are shown in Table 6.

Table 6. Initial support parameters

\begin{tabular}{clllll}
\hline $\begin{array}{c}\text { Depth } \\
(\mathbf{m})\end{array}$ & $\begin{array}{l}\text { Lateral } \\
\text { pressure } \\
\text { coefficient }\end{array}$ & $\begin{array}{l}\text { Safety } \\
\text { degree }\end{array}$ & $\begin{array}{l}\text { Anchor } \\
\text { length }(\mathbf{m})\end{array}$ & $\begin{array}{l}\text { Anchor } \\
\text { spacing } \\
(\mathbf{m})\end{array}$ & $\begin{array}{l}\text { Shotcrete } \\
\text { thickness } \\
(\mathbf{m m})\end{array}$ \\
\hline 60 & 1.5 & 2.0 & 3.0 & 1.1 & 150 \\
\hline
\end{tabular}

Substituting these parameters into Equation (10), we can obtain $F_{V}=2.4$. The optimized parameters can be solved in Table 7 according to the obtained optimization model.

Table 7. Optimized parameters

\begin{tabular}{ccc}
\hline $\begin{array}{c}\text { Anchor length } \\
(\mathbf{m})\end{array}$ & $\begin{array}{c}\text { Anchor spacing } \\
(\mathbf{m})\end{array}$ & $\begin{array}{c}\text { Shotcrete thickness } \\
(\mathbf{m m})\end{array}$ \\
\hline 2.8 & 1.2 & 130 \\
\hline
\end{tabular}

By incorporating the optimized parameters into Equation (11) again, the new $F_{V}=3.2$ is obtained. The material costs 
presented in this paper indicate that the optimal design can save 6.32 million Yuan. The optimized results show that optimization can result in large economic benefits for highspeed railway tunnels.

\section{Conclusions}

1) Six main factors that affect the stability of surrounding rocks were selected for optimization. These factors included surrounding rock level, depth, lateral pressure coefficient, anchor length, anchor spacing, and shotcrete thickness. Five levels of each factor were considered in several orthogonal experiment designs. Satisfactory uniformity results were obtained.

2) An approximate linear model of support parameters and cost-effectiveness was obtained on the basis of a multiple linear regression analysis following a number of numerical experiments. In addition, the effects of the support parameters on the stability of surrounding rocks were analyzed.
3) The regression analysis results were optimized using the least squares method on the basis of the approximate linear model. A multivariate linear function of cost-effectiveness and support parameters was proposed. By substituting the parameters of geological conditions and safety levels into the function, optimized tunnel support parameters were solved.

4) An optimal design of the Liuyang River Tunnel in the Wuhan-Guangzhou Line was developed. After the optimization, the costs of tunnel support are greatly reduced in comparison with the costs under the original scheme. The results of this work can be utilized as a reference for tunnel support, particularly when surrounding rocks are at level IV.

\section{Acknowledgements}

This work was supported by the National Natural Science Foundation of China under the project No. 41401535.

\section{References}

1. Monika R.N., Magnus J., "Merits of using a socio-technical system perspective and different industrial accident investigation methods on accidents following natural hazards", International Journal of Disaster Risk Reduction, 13(3), 2015, pp.189-199.

2. Miltos K., Arnab M., Washington Y.O., "Data based framework to identify the most significant performance shaping factors in railway operations", Safety Science, 78(10), 2015, pp.60-76.

3. Niu F.S., Ma K., Guo Y.J., "Study on surrounding rock classification refinement of railway tunnel and application", Journal of Civil, Architectural \& Environmental Engineering, 35(6), 2013, pp.81-86.

4. Meng Q.B., Han L.J., Sun J.W., Min F.Q., Feng W., Zhou X., "Experimental study on the bolt-cable combined supporting technology for the extraction roadways in weakly cemented strata", International Journal of Mining Science and Technology, 25(1), 2015,pp.113-119.

5. Liu X.B., Han Y.H., "Optimal determination of spray anchor support parameters", Chinese Journal of Rock Mechanics and Engineering, 13(1), 1994, pp.79-89.

6. Xia J.B., Yie J.M., Chen R.H., "Application of neurotic network in parameter optimization of support of mining workings", Yunnan Metallurgy, 32(2), 2003, pp.11-14.

7. Wang C.B., Yang W.B., "Design on mining gateway support base on numerical simulation analysis", Coal Engineering, 366(5), 2009, pp.60-63.

8. Zheng J.J., Liu X.M., Ouyang Y.P., Zhang R.J., "Optimum analysis of large-section tunnel's bolts location by FLAC", Chinese Journal of Underground Space and Engineering, 5(2), 2009, pp.341-346.

9. Wang X., Wang Y., Xia H., "On the optimization of bolt mesh anchor support parameter in complex situation”, China Coal, 36(3), 2010, pp.48-51.

10. Wang S., Li C., Liu Z., Fang J., "Optimization of construction scheme and supporting technology for HJS soft rock tunnel", International Journal of Mining Science and Technology, 24(6), 2014, pp.847-852.

11. Behrooz R., Kourosh S., Mostafa S., "Evaluation of rock mass engineering geological properties using statistical analysis and selecting proper tunnel design approach in Qazvin-Rasht railway tunnel", Tunnelling and Underground Space Technology, 41(3), 2014, pp.206-222.
12. Lu A., Chen H., Qin Y., Zhang N., "Shape optimisation of the support section of a tunnel at great depths", Computers and Geotechnics,61(7),2014,pp.190-197.

13. WEI X., XUE B. , ZHAO Q., "Optimization design of the stability for the plunger assembly of oil pumps based on multi -target orthogonal test design", Journal of Hebei University of Engineering (Natural Science Edition),27(3), 2010,pp.95-99.

14. Lu A., Zhang N., Kuang L., "Analytic solutions of stress and displacement for a non-circular tunnel at great depth including support delay", International Journal of Rock Mechanics and Mining Sciences, 70(6), 2014, pp.69-81.

15. Wang Z., Qiao C., Song C., Xu J., "Upper bound limit analysis of support pressures of shallow tunnels in layered jointed rock strata", Tunneling and Underground Space Technology, 43(3), 2014, pp.171-183.

16. Anirban D., Alberto N., Thomas F., "Numerical and physical modeling of geofoam barriers as protection against effects of surface blast on underground tunnels", Geotextiles and Geomembranes, 44(1), 2015, pp.1-12.

17. Xu Q., Xiao Z., Liu T., Lou P., Song X., "Comparison of 2D and $3 \mathrm{D}$ prediction models for environmental vibration induced by underground railway with two types of tracks", Computers and Geotechnics, 68(7), 2015, pp.169-183.

18. Patrícia L., Alves C., Ferraz M., Calçadaa R., Silva A., "Numerical modeling of vibrations induced by railway traffic in tunnels: From the source to the nearby buildings", Soil Dynamics and Earthquake Engineering, 61(6), 2014, pp.269-285.

19. Fortsakis P., Nikas K., Marinos V., Marinos P., "Anisotropic behavior of stratified rock masses in tunneling", Engineering Geology, 141(7), 2012, pp.74-83.

20. Zhang L., Zheng Y., Wang Z., Wang J., "Application of strength reduction finite element method to road tunnels", Rock and Soil Mechanics, 28 (1), 2007, pp.97-106.

21. Zhao H., Ru Z., Xu C., "Reliability analysis of tunnel using least square support vector machine". Tunnelling and Underground Space Technology, 41(3), 2014, pp.14-23.

22. Zhu Y., Zhang S., Jing S., "Concept and determination of limit displacements of primary support system of railway tunnel". Chinese Journal of Rock Mechanics and Engineering, 24(09), 2005, pp.1594-1598. 